\title{
O enfoque CTSA e uso de Metodologias Ativas no Ensino Superior: uma análise baseada na discussão de notícias sobre acidentes ambientais envolvendo produtos químicos
}

\author{
Cristine Santos de Souza da Silva ${ }^{1}$ \\ Denise Santos de Souza ${ }^{2}$
}

\begin{abstract}
RESUMO
O enfoque CTSA e o uso de Metodologias Ativas estão cada vez mais presentes no Ensino Superior, isso porque são comprovadamente eficientes para o ensino de ciências e para a contextualização de problemáticas atuais. Considerando essas duas abordagens de ensino esse artigo apresenta uma análise de uma atividade realizada com alunos de quatro cursos de graduação, tendo como enfoque os impactos ambientais decorrentes de acidentes envolvendo produtos químicos. A metodologia adotada foi a discussão e análise de notícias jornalísticas atuais associadas ao tema. Como resultado observou-se que mesmo no âmbito do ensino superior, a contextualização é necessária para a compreensão dos pressupostos teóricos que se deseja ensinar. Por meio do enfoque CTSA foi possível constatar os avanços dos alunos no desenvolvimento das habilidades como diálogo, pensamento crítico e compreensão de processos complexos, como os que se referem às questões ambientais.
\end{abstract}

PALAVRAS-CHAVE: Educação Ambiental. Ensino de Ciências. CTSA. Metodologias Ativas. Ensino Superior.

\footnotetext{
1 Doutora em Ensino de Ciências e Matemática. Universidade Luterana do Brasil. Canoas/RS. Brasil. https://orcid.org/0000-0002-8858-1115.cristine3s@hotmail.com.

2 Mestra em Ensino de Ciências e Matemática. Universidade Luterana do Brasil - ULBRA, Canos/RS. Brasil. https://orcid.org/0000-0002-8730-5768.dedessza@gmail.com.
} 
The STSE approach and use of Active Methodologies in Higher

Education: An analysis based on the discussion of news about environmental accidents involving chemical products

\begin{abstract}
The STSE approach and the use of Active Methodologies are increasingly present in Higher Education, because they are proven efficient for the teaching of science and for the contextualization of current problems. Considering these two teaching approaches this article presents an analysis of an activity performed with students from four undergraduate courses, focusing on the environmental impacts resulting from accidents involving chemical products. The methodology adopted was the discussion and analysis of current journalistic news associated with the theme. As a result it was observed that even in the scope of higher education, contextualization is necessary to understand the theoretical assumptions that one wishes to teach. Through the CTSA approach it was possible to verify the advances of students in the development of skills such as dialogue, critical thinking and understanding of complex processes, such as those referring to environmental issues.
\end{abstract}

KEYWORDS: Environmental Education. Science Teaching. Stse. Active Methodologies. Higher Education.

$$
* * *
$$

\title{
Introdução
}

Vive-se na atualidade um momento em que a notícia é dada em tempo real, em que a produção de conteúdo noticioso chega a ser imensurável, e a sociedade é bombardeada por informações através de vários canais: TV, rádio, Internet, revistas, jornais, etc. As notícias são divulgadas numa velocidade intensa em decorrência dos avanços das tecnologias da informação e comunicação, porém, essa aceleração em muitos casos impede uma reflexão mais atenta sobre as informações que chegam através dos canais mencionados. 
Em contrapartida, o ensino por meio da discussão das notícias apresenta benefícios, uma vez que aproxima o aluno do conteúdo e possibilita que as temáticas da atualidade tornem o processo de aprendizagem significativo e relevante.

Essencial na formação dos cidadãos, o Ensino das Ciências possibilita a compreensão da realidade que os cerca. Em um mundo cada vez mais tecnológico, a relação da ciência com a tecnologia nos mais diversificados contextos é cada vez mais notória.

Apesar dos constantes avanços tecnológicos, e da crescente valorização e preocupação com a proteção ambiental, acidentes industriais que ocasionam impactos ambientais eventualmente ocorrem. No que tange aos acidentes industriais envolvendo produtos químicos, os incidentes frequentemente são noticiados na imprensa, e repercutem por causa das vítimas humanas ou dos danos causados ao ambiente.

Considerando isso, o presente artigo apresenta uma análise da aplicação de uma metodologia ativa de ensino realizada com alunos do ensino superior, tendo como enfoque a perspectiva CTSA, relacionada aos impactos ambientais decorrentes de acidentes envolvendo produtos químicos.

\section{O enfoque CTSA de ensino}

As rápidas mudanças decorrentes dos avanços tecnológicos é uma das características mais marcantes da sociedade contemporânea, que tem como principal foco o desenvolvimento humano e social. Este cenário reforça o papel da educação na formação do cidadão, de modo a possibilitar a tomada de decisões, ações e compreensões sobre as tecnologias, e desta maneira, exercer a sua cidadania (SILVA et al., 2016).

Visando a ampla formação do cidadão, surgiu o enfoque educacional CTS (Ciência, Tecnologia e Sociedade), tendo como aspecto central a alfabetização científica e tecnológica. Quando do seu surgimento, em meados 
das décadas de 1960 e 1970, o enfoque CTS objetivava a transformação social através da preparação dos cidadãos, por meio da difusão do conhecimento científico, para as tomadas de decisões em questões públicas. A principal característica do CTS é a integração dos conteúdos de ciências com o contexto social e tecnológico por meio da discussão dos aspectos históricos, políticos, éticos e socioeconômicos (FAGUNDES et al., 2000; SANTOS; MORTIMER, 2002). Em relação ao CTS, Bourscheid e Farias (2014, p.8) afirmam que:

Quanto à abrangência, a CTS é uma proposta pedagógica que desvincula a ideia de ciência neutra, aproxima a realidade ao aluno, trazendo significado para aquilo que é estudado, de modo que os conteúdos e o ensino de conceitos aparecem como via para dar sentido àquilo que é questionado, centrando-se em temas de relevância social.

Contudo, além de estimular a discussão acerca das questões tecnológicas e científicas, o movimento CTS acabou por favorecer um pensamento mais amplo em relação ao agravamento dos problemas ambientais decorrentes das atividades humanas sobre a natureza, fazendo com que fosse incorporado a proposta inicial, uma perspectiva de reflexão ambiental chamada de CTSA (Ciência, Tecnologia, Sociedade e Ambiente) (PINTO; SGARBI, 2016).

A junção do enfoque CTS com a EA (Educação Ambiental) foi possível devido suas metas fundamentarem-se de forma congênere, uma vez que, ambas admitem a importância da formação do cidadão preparado para a tomada de decisão acerca de questões atuais por meio de um processo educacional que envolva ciência e tecnologia (GONZALEZ, 2011).

No que tange o ensino de ciências, o enfoque CTSA possui uma validade cultural e uma validade científica, indo além de uma aprendizagem de conceitos e de teorias que estejam relacionadas com conteúdos canônicos, 
tendo por alvo, ensinar o essencial para que se atinja o aproveitamento das contribuições de uma educação científico-tecnológica. A vinculação dos conteúdos científicos com temas CTSA de relevância social e a abertura de espaços em sala de aula para debates que envolvam questões sócio científicas são ações indispensáveis no processo do desenvolvimento de uma educação crítica e questionadora (BOURSCHEID; FARIAS, 2014; TOMAZELLO, 2009).

Somente por meio de uma educação científica, que vincule o conhecimento científico, a tecnologia, a sociedade e o meio ambiente é possível formar cidadãos capazes de discernir os impactos de suas escolhas, assim como, consequências pertinentes ao conhecimento e sua aplicabilidade (FERNANDES; PIRES, 2012). Outrossim, Bourscheid e Farias (2014, p.9) defendem que "é imprescindível uma abordagem que considere o embasamento teórico para relacioná-lo com a prática, pois toda a prática necessita de suporte, fundamentação", e Fagundes et al. (2000) complementam ao afirmar que mais que aprender a ler e escrever, o cidadão precisa aprender a fazer uma leitura crítica do mundo em que vive.

Inúmeras são as estratégias de ensino fundamentadas no CTSA, porém, o conteúdo abordado deve estar centrado em proposições de relevância social que possibilitem o desenvolvimento do senso de responsabilidade, essencial para a formação do cidadão capaz de tomar decisões. Atividades que objetivem a solução de problemas, simulações, exercícios de tomada de decisões, que apresentem situações controversas, ou mesmo, a realização de debates, individuais ou em grupos, realizadas por meio de discussões em aula, utilizando metodologias ativas e recursos tecnológicos são imprescindíveis nos processos educacionais CTSA (FAGUNDES et al., 2000; GONZALEZ, 2011).

Nesse contexto, o desenvolvimento de temas concernentes à ciência e à tecnologia podem ser trabalhados por meio da divulgação científica, mediante a leitura de textos que não estão presentes apenas nos livros didáticos, mas os que estão contidos nos jornais e revistas, por exemplo. 


\section{Metodologias Ativas no ensino superior}

$\mathrm{Na}$ sociedade contemporânea, os métodos tradicionais baseados na transmissão de informações pelos professores não fazem mais sentido, uma vez que tiveram sua valia quando o acesso à informação era difícil. Com o advento da tecnologia o ensino atual exige uma interligação simbiótica, profunda e constante entre o que chamamos mundo físico e mundo digital. Neste contexto, um novo olhar sobre as formas contemporâneas de realizar a transposição didática significativa e o papel do professor no processo de ensino e aprendizagem precisa ser discutido (ROCHA; LEMOS, 2014).

Partindo de uma concepção educacional em que o estudante é o protagonista do seu aprendizado, podemos colocar em evidência as metodologias ativas. Por meio delas, o estímulo à crítica e à reflexão são incentivados por meio da intervenção do professor. Diversos autores concordam que o aspecto que favorece o aprendizado é sua característica participativa, que além de tornar o ensino interessante faz com que a autonomia individual do aluno seja desenvolvida (BARBOSA; MOURA, 2013; MORÁN, 2015; ROCHA; LEMOS, 2014; VALENTE; ALMEIDA; GERALDINI, 2017).

Nas referências que tratam desta temática, as metodologias ativas são apresentadas como estratégias pedagógicas que colocam o foco no aprendiz e que por este motivo, são contrastantes com a abordagem tradicional de ensino, em que o professor é o centro do processo. De acordo com Valente, Almeida e Geraldini (2017), as metodologias ativas criam situações de aprendizagem em que os alunos podem de forma autônoma agir, pensar e conceituar suas ações, na medida em que colocam o conhecimento em prática. Possibilitando a aprendizagem dos conteúdos e pressupostos teóricos envolvidos nas atividades que estão sendo realizadas por meio da interação com os colegas e com o professor de forma interativa, considerando que atitudes e valore coletivos também são necessários às suas formações. 
As metodologias ativas possuem o potencial de despertar a curiosidade, à medida que os alunos se inserem na teorização e trazem elementos novos, que por ventura, ainda não tinham sido considerados nas aulas ou na própria perspectiva do professor, tornando-se assim, um instrumento didático desafiador tanto para quem aprende quanto para quem ensina. O papel do professor no uso desta metodologia, além de mediar a discussão e estimular a pesquisa autônoma dos estudantes, é analisar de forma crítica e contributiva as descobertas dos alunos, valorizando-as e estimulando o sentimento de engajamento, enaltecendo nos aprendizes a percepção de pertencimento ao grupo e da sua importância no processo educacional (ROCHA; LEMOS, 2014).

Segundo Barbosa e Moura (2013) não importa a estratégia que será adotada para o exercício das metodologias ativas, o essencial é que o aluno faça uso de suas funções mentais, relacionadas ao pensamento, ao raciocínio, a observação e a reflexão, de forma que possam entender o conteúdo que se pretende ensinar, desenvolvendo em si a inteligência de forma autônoma. Sendo, portanto, esta atitude ativa da inteligência a diferença fundamental que caracteriza um ambiente de aprendizagem ativa, em contraposição à atitude passiva geralmente associada aos métodos tradicionais de ensino.

Sobre a aprendizagem nesse contexto, educar para a autonomia significa um ato político-pedagógico argucioso para os campos de formação de professores e profissionalização dos alunos, uma vez que, os desafios propostos por meio da prática das metodologias ativas, quando bem planejados, contribuem para mobilizar as competências desejadas pelo processo de ensino, pois trabalham atributos intelectuais, emocionais, pessoais e comunicacionais. Elas exigem aos aprendizes que realizem pesquisas, avaliem situações, discutam pontos de vista diferentes, façam escolhas, assumam alguns riscos, e desta forma, aprendam pela descoberta (BERBEL, 2011; MORAN, 2015).

Sendo assim, o papel do professor é contribuir para promover a autonomia do aluno em sala de aula, nutrindo os recursos motivacionais 
internos, relacionados aos interesses pessoais dos alunos, oferecer explicações que subsidiem os estudos em relação ao conteúdo ou sobre a atividade proposta. Além disso, também é fundamental que ele use linguagem informacional e atue de forma mediadora e não controladora, sendo paciente com o ritmo de aprendizagem dos alunos (BARBOSA; MOURA, 2013; BERBEL, 2011).

\section{O ensino por meio da discussão de notícias jornalísticas}

Trabalhar com notícias jornalísticas tem o intuito de proporcionar ao educando momentos de análise de informações, além de possibilitar correlacioná-las aos conteúdos que se quer ensinar. Neste viés, o processo de ensino permite, além de abordar temas atuais, fazer uma reflexão crítica acerca das transformações contemporâneas que o mundo está passando, situando o educando quanto aos reflexos dessas transformações na sua vida (ANHUSSI, 2009).

As reportagens publicadas pelas mídias são fontes de informações que estão interligadas com os temas do ensino, pois fazem referência a assuntos econômicos, sociais, ambientais, culturais, entre outros. O jornal impresso ou digital, por exemplo, faz parte do dia-a-dia do aluno, por isso, é um instrumento pedagógico que possibilita aos estudantes superar o senso comum, levando-os a uma leitura mais crítica do mundo que os cerca. Por meio da análise do seu conteúdo o aluno poderá fazer comparações, relacionar notícias, selecionar informações e até mesmo levantar hipóteses sobre o que está sendo lido (PAROLI, 2006).

Neste contexto, Ostrovski (2009) afirma que o correlacionamento do que se quer ensinar com as notícias midiáticas possibilita ao aluno o desenvolvimento de um olhar mais apurado, mais aguçado que colaborará para que o mesmo não seja influenciado e nem manipulado pela mídia. Isto porque o trabalho consciente realizado por meio das notícias contribui com o amadurecimento do aluno como cidadão, pois as reportagens jornalísticas 
são um recurso didático pedagógico que pode fazer uma interação entre a realidade do aluno com os conteúdos desenvolvidos dentro da sala de aula (DE PAULA, 2014).

A mídia se constitui como uma fonte de informações sobre o meio ambiente para a maioria das pessoas, sendo, portanto, inegável sua importância no desencadeamento dos debates que podem gerar transformações e soluções efetivas dos problemas locais. Por este motivo, o uso de notícias e reportagens para o ensino de ciências, sejam notícias de TV e de rádio, de jornais e revistas, quanto de programas especiais tratando de questões relacionadas ao meio ambiente têm sido cada vez mais frequentes, favorecendo, dessa maneira, a utilização destes recursos em sala de aula. Fazer uso dessas ferramentas de informação pode ser uma boa estratégia para trabalhar a educação ambiental, uma vez que possibilita trazer para dentro da sala aula assuntos atuais e relevantes (CARNEIRO; FARIA; SHUVARTZ, 2009).

Especificamente, no que diz respeito a perspectiva CTSA de ensino e ao uso de notícias jornalísticas como metodologia educacional, Tomazello (2009) explica que originalmente há um descompasso entre a ciência publicizada da mídia e a ciência trabalhada na escola, sendo portanto, um caminho promissor usar o ambiente escolar para a discussão das questões do cotidiano, fazendo isso de forma crítica e dialogada.

\section{Acidentes ambientais envolvendo produtos químicos}

Acidentes ambientais são conceituados como eventos não previstos, que são capazes de direta ou indiretamente, causarem danos a saúde humana ou ao meio ambiente. Episódios como lançamentos ou vazamentos indevidos de substâncias (gasosas, líquidas ou sólidas) nos corpos d’água, no solo ou na atmosfera, incêndios em instalações industriais ou florestas, são exemplos de acidentes ambientais. Quando da ocorrência desses fatos, de acordo com Sánchez (2015), faz-se necessário que amostras sejam coletas 
para a realização da avaliação do dano ambiental, e consequentemente, ações remediativas sejam desenvolvidas, assim como, a responsabilização dos causadores do acidente seja possibilitada.

No que tange a indústria química, a partir da II Guerra Mundial houve um grande incremento nesta área em decorrência da necessidade de novos materiais e produtos. O desenvolvimento e a expansão do complexo químico industrial resultaram principalmente da mudança da base de carvão para o petróleo, da influência do setor industrial na economia mundial e dos constantes avanços tecnológicos. Outrossim, paralelamente ao crescimento da indústria química, houve o aumento na frequência e na gravidade dos acidentes químicos (FREITAS; AMORIM, 2001; FREITAS; PORTE, 1995; NARDOCCI; LEAL, 2006).

Em relação aos acidentes químicos, Freitas e Amorim (2001, p.2) afirmam que:

Esses acidentes podem ocorrer em instalações fixas (unidades de produção industrial ou de armazenamento) ou durante o transporte de substâncias químicas (rodoviário, ferroviário, hidroviário, aeroviário e dutoviário), possuindo a capacidade de a gravidade e a extensão dos seus efeitos ultrapassarem os seus limites espaciais - de bairros, cidades e países - e temporais - como a teratogênese, carcinogênese, mutagênese e danos a órgãos alvos específicos.

Acidentes que evolvem produtos químicos são geralmente classificados como "Acidentes Ampliados", e esta caracterização é originária do potencial de expansão que esses fenômenos possuem. Casualidades com produtos químicos de forma geral, apresentam em sua maioria propensão á incêndios, explosões e vazamentos, que podem ocorrer de forma isolada ou combinada, envolvendo uma ou mais substâncias perigosas (FREITAS; PORTE, 1995). 
Múltiplos danos ao meio ambiente e à saúde das pessoas podem ser ocasionados pelos acidentes que envolvem produtos químicos. Em relação aos impactos ambientais, estudos apontam que os mais graves estão associados ás emissões de gases tóxicos e poluentes, tendo como consequência as chuvas ácidas, a destruição da camada de ozônio, as alterações no efeito estufa, entre outros. Contudo, salienta-se que, apesar das atividades que envolvem produtos químicos serem constantemente associadas, direta ou indiretamente, aos impactos ambientais, diversas outras atividades humanas também são responsáveis pela degradação e poluição do meio ambiente (FREITAS; PORTE, 1995; LENARDÃO et al., 2003).

No que concerne a responsabilização dos acidentes químicos industriais, Freitas e Amorim (2001) afirmam que, na maioria dos casos, as vítimas são responsabilizadas, ou seja, os trabalhadores. Ademais, defendem a necessidade da adoção de medidas preventivas, assim como, quando da ocorrência de acidentes, a realização de avaliações acerca dos impactos ao meio ambiente e a saúde.

\section{Metodologia da Pesquisa}

O presente estudo foi realizado em uma instituição de ensino superior, na disciplina denominada "Impacto Ambiental e Análise de Riscos - IAAR", a qual é obrigatória para dois cursos de graduação, Engenharia Ambiental e Engenharia Civil, e eletiva para os cursos de Agronomia, Arquitetura e Biologia. A disciplina possui, como característica, uma ênfase teórico-prática, baseada na discussão e análise de estudos de casos reais.

Neste sentido, considerado a importância de contextualizar o ensino, conforme prevê a abordagem CTSA, definiu-se então que o conteúdo relacionado a temática dos impactos ambientais seria abordado por meio da aplicação de uma metodologia ativa de ensino, cuja estruturação envolvia a utilização de notícias jornalísticas atuais, veiculadas nas mídias, que 
referissem os impactos ambientais ocasionados por acidentes que envolvessem produtos químicos.

Optou-se pela pesquisa por acidentes que envolvessem produtos químicos em decorrência da amplitude de possibilidades que a temática apresenta, uma vez que, os produtos químicos estão presentes em diversos meios.

Em um primeiro momento, visando proporcionar um aporte teórico a respeito dos conteúdos a serem trabalhados na disciplina, foram ministradas três aulas teórico-expositivas acerca dos conceitos básicos, a saber: 1) Ambiente, degradação e poluição; 2) Levantamento de aspectos e impactos ambientais; 3) Risco ambiental e gerenciamento de riscos ambientais.

Posteriormente, como atividade prática, solicitou-se que os alunos pesquisassem cinco notícias recentes, com menos de 5 anos de publicação, que discorressem acerca de acidentes ambientais que envolvessem produtos químicos, e, analisassem de forma crítica as notícias. A atividade requeria que os alunos, a partir do que fosse noticiado nas reportagens, investigassem quais aspectos e impactos ambientais estariam associados ao acidente.

Conforme já mencionado, por se tratar de uma atividade estruturada de acordo com os preceitos de uma metodologia ativa de ensino, o professor não pode ser a única fonte de informação e conhecimento, baseado nisto, buscou-se atuar de maneira a orientar, supervisionar e/ou facilitar a aprendizagem dos estudantes (BARBOSA; MOURA, 2013).

Como fechamento da ação, as notícias e suas respectivas análises foram apresentadas á turma, e subsequentemente, realizou-se discussões acerca das notícias apresentadas, dos aspectos e impactos ambientais identificados, assim como, esclarecimentos acerca dos conteúdos abordados nas aulas teóricas.

De posse dos dados apresentados, por fim, realizou-se a análise dos dados da presente pesquisa. Para isso, o método adotado foi a análise de conteúdo, que segundo Bardin (2011), é um conjunto de técnicas de análise 
das comunicações que utiliza procedimentos sistemáticos e objetivos de descrição do conteúdo das mensagens. Diante disso, os resultados das pesquisas dos alunos foram categorizados de acordo com a prevelacencia dos assuntos trazidos, conforme demonstra a Tabela 1:

TABELA 1: Categorias para classificação das notícias

\begin{tabular}{l|l}
\hline Categoria & Descrição \\
\hline $\begin{array}{l}\text { Emissões } \\
\text { Atmosféricas }\end{array}$ & $\begin{array}{l}\text { Acidentes que envolvem vazamentos de gases na atmosfera. ou } \\
\text { que em função destes, ocasionaram explosões, intoxicação ou } \\
\text { incêndios. }\end{array}$ \\
\hline $\begin{array}{l}\text { Vazamento } \\
\text { de Óleo }\end{array}$ & $\begin{array}{l}\text { Acidentes que envolvem o vazamento de óleo ou combustíveis no } \\
\text { recurso hídrico ou no solo. }\end{array}$ \\
\hline Resíduos & $\begin{array}{l}\text { Acidentes que envolvem o derramamento de resíduos sólidos, } \\
\text { semissólidos ou líquidos, ou rejeitos, das atividades industriais, } \\
\text { tanto no recurso hídrico como no solo. }\end{array}$ \\
\hline $\begin{array}{l}\text { Qarga } \\
\text { Química }\end{array}$ & $\begin{array}{l}\text { Acidentes de trânsito que envolvem veículos de carga de } \\
\text { produtos químicos, sejam líquidos ou gases, com derramamento } \\
\text { (ou vazamento) na via em que é necessário o acionamento de } \\
\text { plano de contingência/emergência. }\end{array}$ \\
\hline Nuclear & $\begin{array}{l}\text { Acidentes que em usinas nucleares ou que envolvem elementos } \\
\text { radioativos. }\end{array}$ \\
\hline Agrotóxicos & $\begin{array}{l}\text { Acidentes que envolvem produtos químicos agrotóxicos, como: } \\
\text { fertilizantes, pesticidas, herbicidas, entre outros, independente } \\
\text { da via de contaminação/exposição. }\end{array}$ \\
\hline Não Atende & Acidentes que não atendem ao que foi solicitado na atividade. \\
\hline Fonte: Siva Soura
\end{tabular}

Fonte: Silva e Souza, 2019.

\section{Resultados e Discussão}

Participaram da pesquisa os alunos de duas turmas da disciplina de Impacto Ambiental e Análise de Risco - IAAR do primeiro semestre de 2017, perfazendo ao todo 40 alunos. No referido semestre a disciplina teve integrantes dos cursos de: Engenharia Civil, com um total de 22 alunos; Engenharia Ambiental, com 10 alunos participantes; Biologia, com 5 alunos; 
e Arquitetura, com apenas 3 alunos. A Figura 1 apresenta o percentual de alunos participantes por curso de formação.

FIGURA 1: Alunos por curso de formação

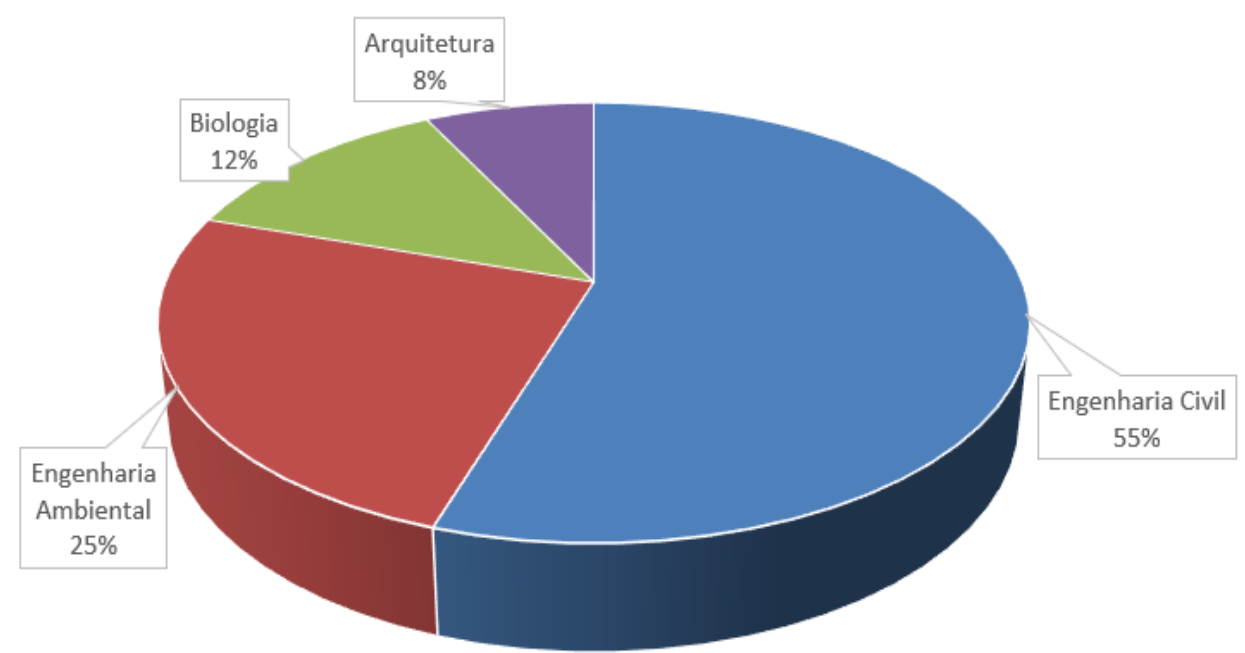

Fonte: Silva e Souza, 2019.

Considerando os resultados apresentados pelos alunos, e que cada aluno deveria pesquisar 5 notícias, foram analisadas ao todo 200 reportagens. A Figura 2 apresenta em valores numéricos e percentuais o resultado da atividade, de acordo com as categorias.

FIGURA 2: Número de notícias apresentadas em cada categoria

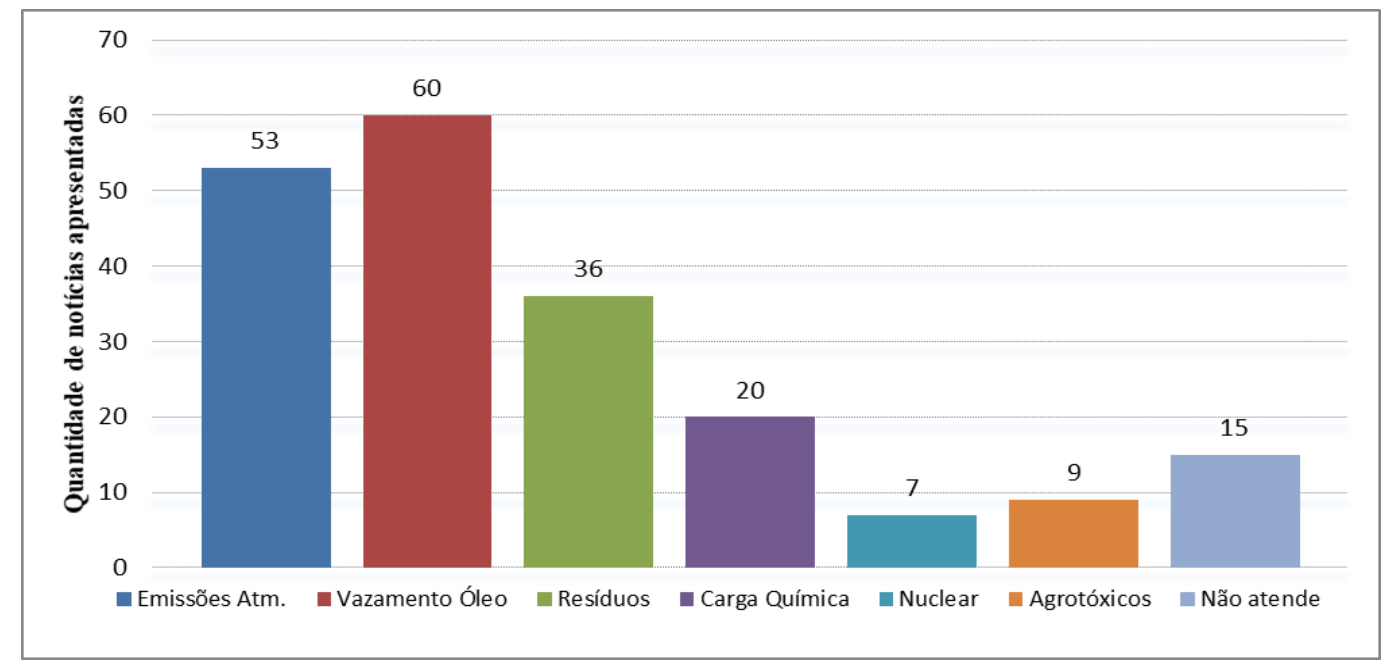

Fonte: Silva e Souza, 2019. 
Constatou-se que a maior parte dos trabalhos apresentados remetiam a acidentes relacionados a vazamentos de óleo (30\%), seguido dos associados ás emissões atmosféricas (26,5\%), e em terceiro lugar, as notícias relacionadas a resíduos/efluentes (18\%). Surpreendeu o fato do baixo índice de reportagens que faziam referência a acidentes envolvendo os agrotóxicos, que ficou em penúltimo lugar, com apenas 4,5\%.

No intuito de identificar os conhecimentos adquiridos durante a formação acadêmica dos diferentes cursos dos alunos acerca da relação da temática ambiental com o uso de produtos químicos, foi analisado a quantidade de notícias apresentadas em cada categoria de acordo com o curso de formação dos alunos (Figura 3).

FIGURA 3: Notícias em cada categoria, de acordo com o curso de formação

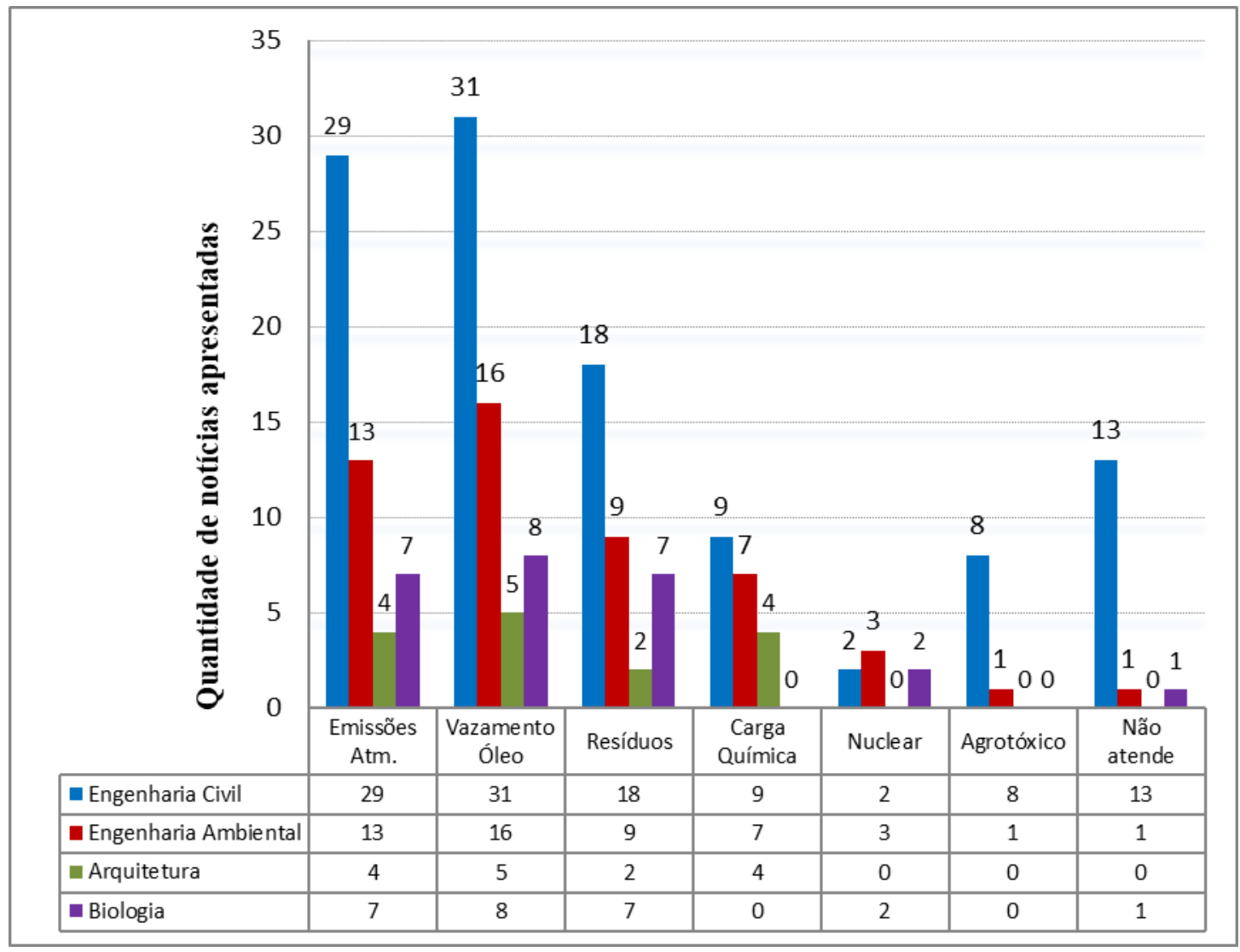

Fonte: Silva e Souza, 2019. 
Em relação a distribuição das notícias apresentadas versus curso de formação dos alunos, chamou atenção o alto índice de notícias trazidas pelos alunos do curso de Engenharia Civil que não atendiam ao que foi proposto na atividade, esse fato se explica por ser a disciplina de IAAR a primeira e única disciplina do curso relacionada a temática ambiental, contrariando o que ocorre no cursos de Engenharia Ambiental e no curso de Biologia, por exemplo.

Os alunos do curso de Arquitetura, com três representantes na disciplina de IAAR e que estavam cursando o $10^{\circ}$ semestre, ao realizarem o trabalho escolheram, em sua maioria, as notícias que remetem a acidentes envolvendo vazamento de óleo (33,5\% dos casos), seguido por acidentes com carga química e emissões atmosféricas (ambas categorias com 26,5\% das notícias apresentadas) e acidentes envolvendo resíduos/efluentes (13,5\%). Notícias sobre acidentes nucleares ou envolvendo agrotóxicos, não foram selecionadas por estes alunos (Figura 4).

FIGURA 4: Notícias apresentadas pelos alunos do curso de Arquitetura

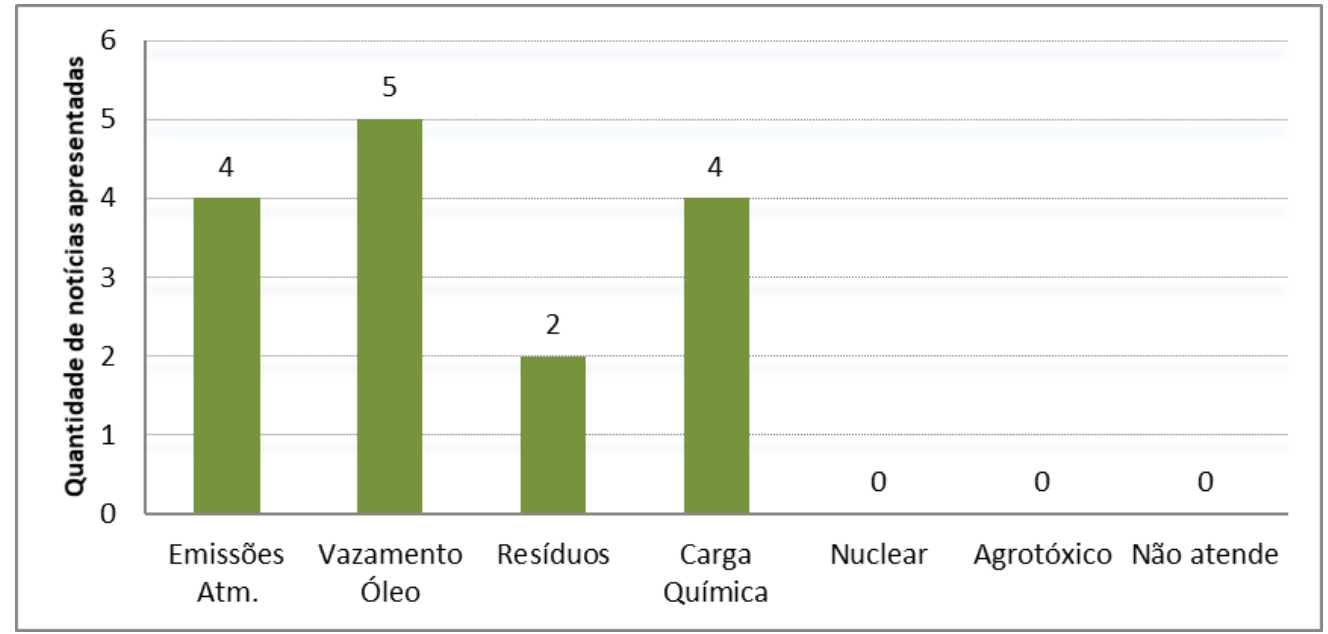

Fonte: A pesquisa.

Os alunos do curso de Biologia, com 5 representantes na disciplina de IAAR, estavam no $8^{\circ}$ semestre, e assim como os demais alunos, também 
apresentaram mais notícias relacionadas a acidentes envolvendo vazamento com óleo, porém contrariando os resultados apresentados pelos alunos do curso de Arquitetura, não apresentaram nenhuma notícia sobre acidente com cargas químicas. Contudo o que mais chama a atenção em relação aos estudantes do curso de Biologia foi o fato de não terem apresentado nenhuma notícia acerca dos acidentes envolvendo o uso de agrotóxicos, uma vez que este é um tema bastante trabalhado em várias disciplinas do curso, como genética, ecologia, química ambiental, botânica, entre outras (Figura $5)$.

Figura 5: Notícias apresentadas pelos alunos do curso de Biologia

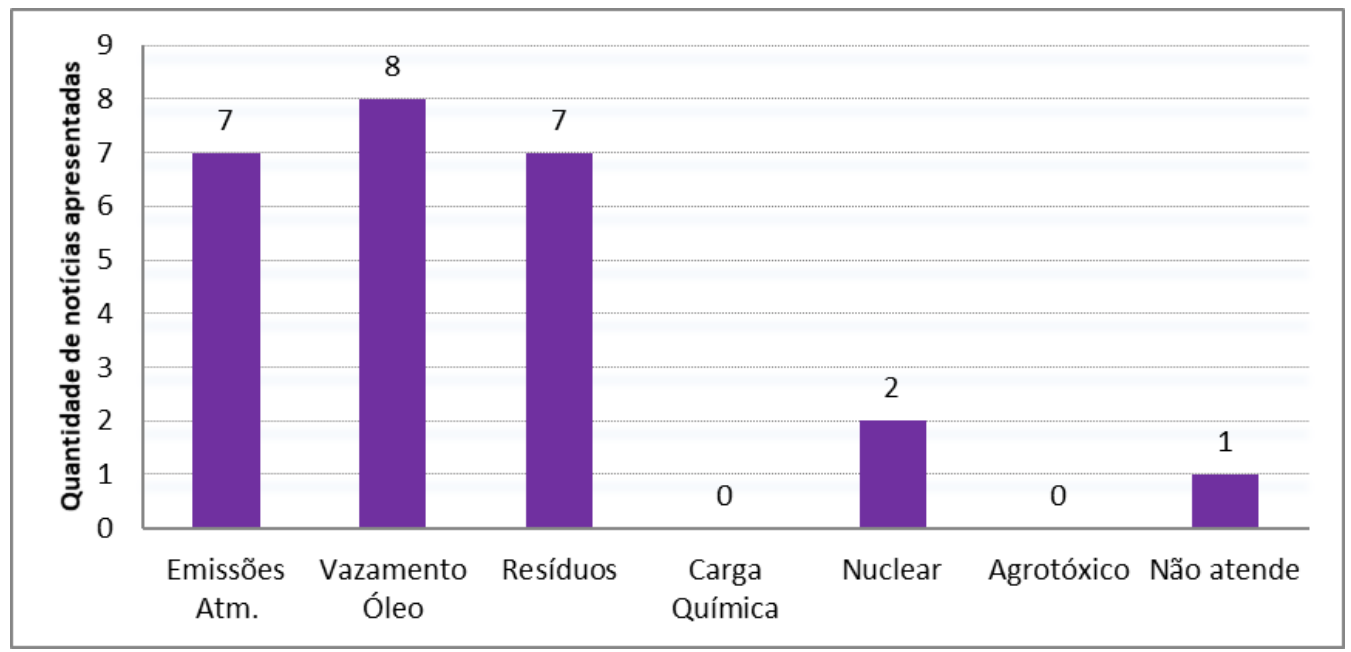

Fonte: Silva e Souza, 2019.

Em relação aos alunos do curso de Engenharia Ambiental, que possuíam 10 representantes e estão, via de regra, cursando entre o $6^{\circ}$ e $8^{\circ}$ semestre na disciplina de IAAR, foi possível perceber uma maior variedade de notícias, não tendo nenhuma das categorias ficado de fora em suas apresentações. Contudo, os acidentes envolvendo vazamento de óleo foram os mais lembrados por eles (32\% das notícias), seguidos por acidentes envolvendo emissões atmosféricas (26\%), acidentes envolvendo resíduos/efluentes (18\%) e cargas químicas (14\%). Ademais, 6\% das notícias eram sobre energia nuclear, $2 \%$ abordavam a temática agrotóxico, e apenas 
$2 \%$ não atenderam o solicitado na atividade. No gráfico da Figura 6 é possível observar os resultados dos alunos do curso de Engenharia Ambiental.

FIGURA 6: Notícias apresentadas pelos alunos do curso de Engenharia Ambiental

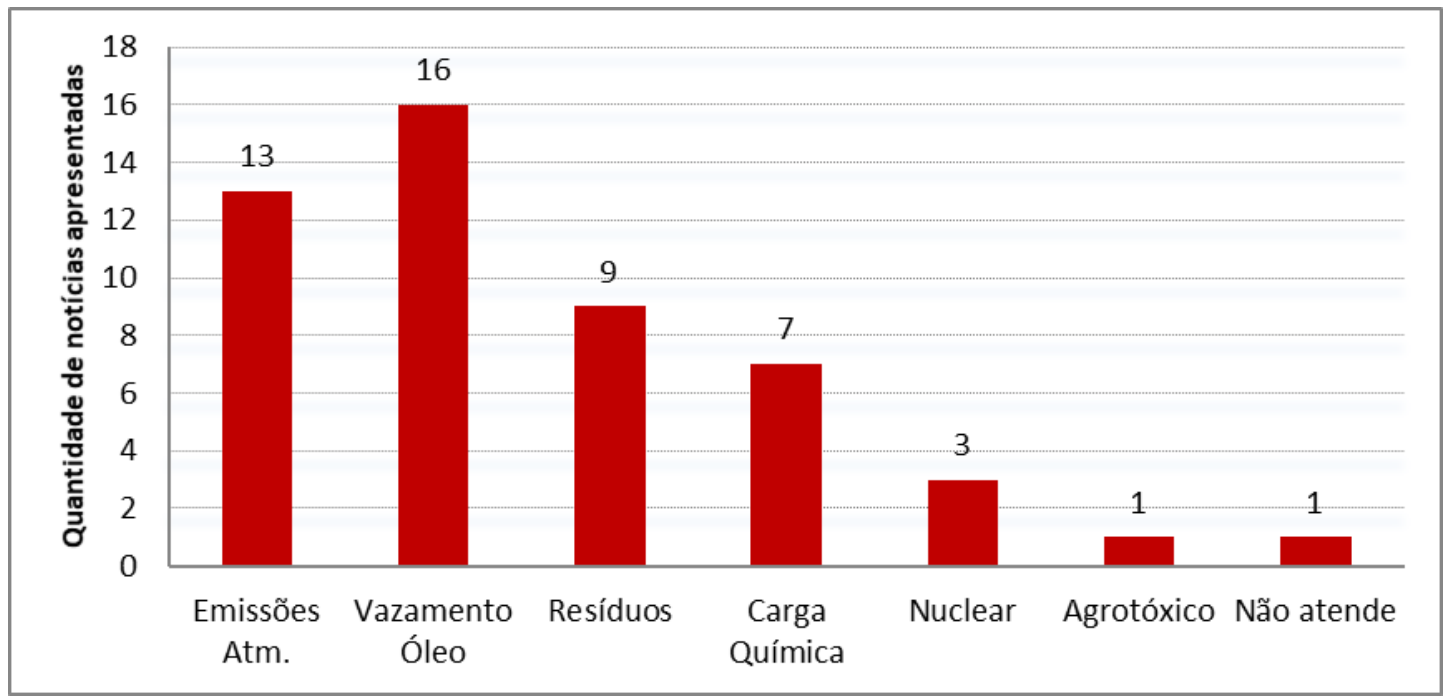

Fonte: Silva e Souza, 2019.

Estes resultados representam um dado importante, pois a capacidade de percepção das relações entre aspectos e impactos ambientais é uma das competências básicas esperadas para um profissional da engenharia ambiental, uma vez que durante todo o curso são abordadas, nas diversas disciplinas do currículo, os aspectos presentes nas categorias mencionadas na atividade proposta neste artigo.

Com relação aos alunos dos outros cursos participantes da disciplina de IAAR, sem sombra de dúvida, os alunos do curso de Engenharia Ambiental são os que possuem mais vantagem em relação à bagagem de conhecimento já incorporada em todo seu processo de formação, uma vez que desde as primeiras disciplinas do curso vem sendo trabalhadas com eles as temáticas dos resíduos, dos poluentes, dos efluentes, das emissões, dos riscos e da gestão ambiental industrial. 
Em relação a formação e preparo dos indivíduos para o trabalho no mundo contemporâneo, Barbosa e Moura (2013) salientam que, além de competências técnicas, é essencial que os profissionais sejam capazes de exercer valores, sejam éticos, possuam iniciativa, sejam criativos e empreendedores, flexíveis, capazes de se expressar de forma oral e escrita, entre outros.

Por fim, com maior número de participantes na disciplina, 22 ao todo, estão os estudantes do curso de Engenharia Civil, que cursam a disciplina de IAAR no seu último semestre de graduação, ou seja, a maioria dos alunos são formandos cursando o $10^{\circ}$ semestre. Os resultados deste grupo de alunos reforçam a importância de se trabalhar de forma mais assertiva as questões relativas ao ambiente no curso de Engenharia Civil, uma vez que é sabido que é esta a atividade industrial que causa mais impactos aos ecossistemas naturais, em função da urbanização e de suas consequências (Figura 7).

FIGURA 7: Notícias apresentadas pelos alunos do curso de

Engenharia Civil

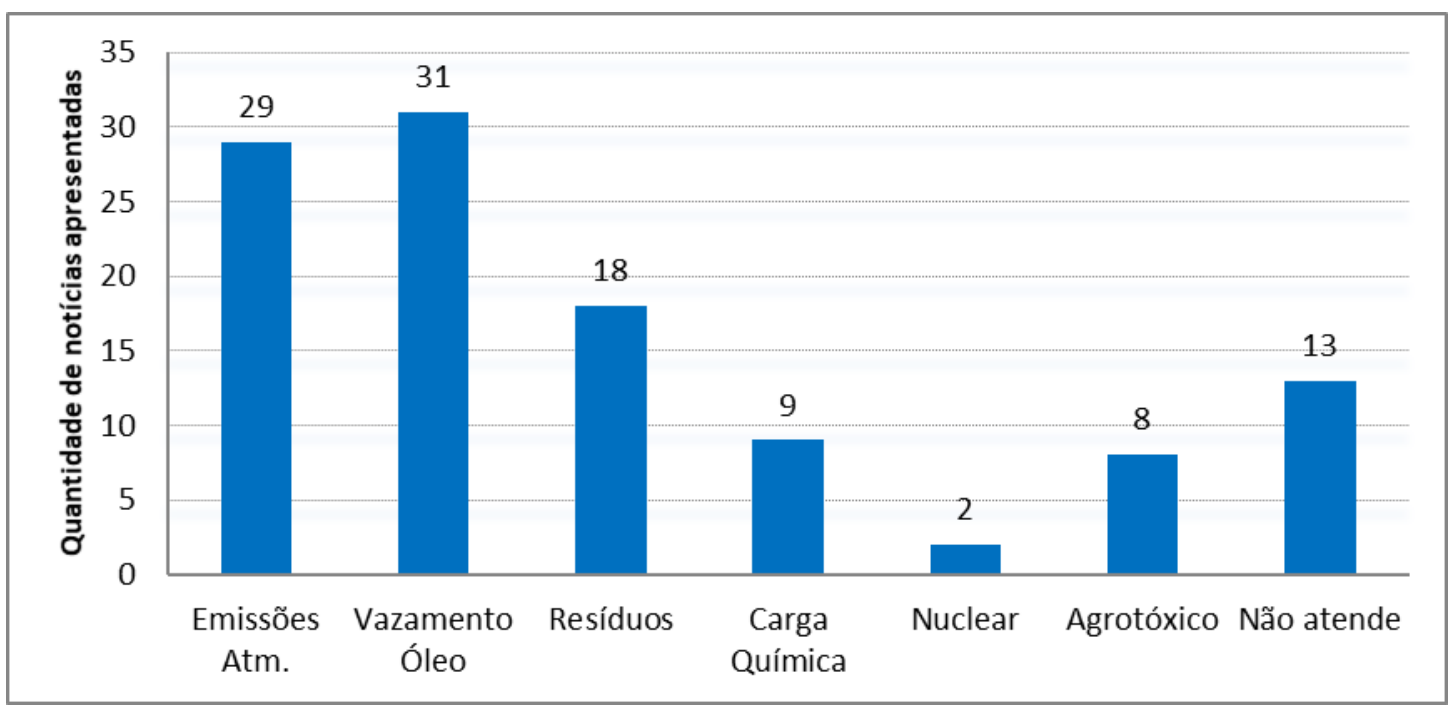

Fonte: Silva e Souza, 2019.

Percebeu-se nesta pesquisa que uma grande quantidade de notícias apresentadas pelos alunos não estavam de acordo com o que foi solicitado na atividade ( $12 \%$ do total), evidenciando a pouca familiaridade deles com a 
temática ambiental. Cabe salientar que esta atividade foi realizada na terceira aula do semestre e que a disciplina de IAAR é a única do curso voltada as questões do ambiente e aos impactos ambientais das atividades humanas, o que pode ser uma justificativa para este índice observado.

Com relação as notícias apresentadas que atendiam ao solicitado na atividade, novamente, as notícias relacionadas a acidentes envolvendo vazamento de óleo (28\%) e emissões atmosféricas (26\%) foram as mais presentes. Também vale destacar o fato de ser este o grupo de alunos que mais relacionou notícias referentes a acidentes ambientais com produtos químicos à utilização de agrotóxicos (7,3\%), contrariando o que foi demonstrado pelos resultados dos outros cursos.

Analisando a atividade realizada com todos os alunos, foi possível perceber que por meio da contextualização e da problematização de questões cotidianas, que a aprendizagem pode se tornar mais significativa. Isto porque, na medida em que as apresentações das notícias selecionadas iam ocorrendo, muitos impactos ambientais associados aos acidentes podiam ser discutidos com o grande grupo, fazendo com que conceitos associados a temática ambiental que pareciam mais complexos pudessem ser elucidados e o conhecimento solidificado, mesmo para aqueles alunos que estavam tendo contato pela primeira vez com os termos da área ambiental, como é o caso dos estudantes dos cursos de Engenharia Civil e Arquitetura.

Durante a apresentação dos trabalhos, a professora atuou como mediadora das discussões, apenas intervindo para corrigir eventuais conflitos em relação a conceitos errados ou percepções distorcidas, possibilitando que os alunos adquirissem uma compreensão contextualizada dos conteúdos teóricos que foram trabalhados na disciplina, assim como, a base para os assuntos que seriam abordados futuramente na disciplina, de modo a facilitar o processo de aprendizagem.

\section{Considerações Finais}


Esta pesquisa permitiu observar os resultados da aplicação de uma metodologia ativa de ensino, considerando a perspectiva CTSA. Embora os resultados majoritários tenham sido semelhantes, algumas particularidades em relação as diferentes percepções dos alunos dos cursos de engenharia civil, engenharia ambiental, arquitetura e biologia, acerca dos impactos ambientais causados por acidentes envolvendo produtos químicos, puderam ser observadas.

A questão maior que pode ser considerada a partir deste trabalho é a necessidade de se trabalhar a temática ambiental de forma contextualizada para que se possa proporcionar ao aluno o entendimento sobre a relevância do estudo acerca das questões do ambiente independente do curso de formação que tenha sido de sua escolha, sabendo que o ambiente sempre exercerá influência sobre a vida das pessoas, direta ou indiretamente.

A discussão dos acidentes trazidos possibilitou o esclarecimento das dúvidas acerca dos conteúdos ensinados nas aulas teóricas e, a partir dos questionamentos dos alunos, foram abordadas questões interdisciplinares sobre tema estudado, bem como foi possível a troca de experiências e conhecimentos entre os próprios grupo de alunos.

Percebeu-se também que, esta atividade possibilitou o desenvolvimento e aprimoramento das habilidades de pesquisa e do espírito científico nos alunos. Ademais, observou-se que é possível por meio de abordagens de ensino mais dinâmicas, como o enfoque CTSA, e mais independentes do protagonismo do professor, como por meio das Metodologias Ativas, tornar a aprendizagem mais significativa e impactante ao aluno, bem como promover o desenvolvimento das habilidades como diálogo, pensamento crítico e compreensão de processos complexos, como os que se referem às problemáticas ambientais.

\section{Referências}

ANHUSSI, E. C. O uso do jornal em sala de aula: sua importância e concepções de professores. [s.l.] Universidade Estadual Paulista, 2009. 
BARBOSA, E. F.; MOURA, D. G. DE. Metodologias ativas de aprendizagem na educação profissional e tecnológica. Boletim Técnico do Senac, v. 39, n. n.2, p. 3847, 2013.

BARDIN, L. Análise de conteúdo. São Paulo: Edições 70, 2011.

BERBEL, N. A. N. As metodologias ativas e a promoção da autonomia de estudantes. Semina: Ciências Sociais e Humanas, v. 32, n. 1, p. 25-40, 2011.

BOURSCHEID, J. L. W.; FARIAS, M. E. A convergência da educação ambiental, sustentabilidade, ciência, tecnologia e sociedade (CTS) e ambiente (CTSA) no ensino de ciências. Revista Thema, v. 11, n. 01, p. 24-36, 2014.

CARNEIRO, E.; FARIA, R. L. DE; SHUVARTZ, M. A utilização da mídia impressa no ensino de ciências: uma proposta de debate sobre o meio ambiente. III EDIPE Enontro Estadual de Didática e Prática de Ensino. Anais...Goiânia, GO: 2009

DE PAULA, C. P. O uso de jornal como instrumento pedagógico no ensino de Geografia. In: Os desafios da escola pública paranaense na perspectiva do professor PDE. [s.l: s.n.]. p. 42.

FAGUNDES, S. M. K. et al. Produções em educação em ciências sob a perspectiva CTS/CTSA. VII ENPEC. Anais...2000

FERNANDES, I. M. B.; PIRES, D. M. Integração CTSA em Manuais Escolares de Ciências da Natureza do 5o ano de Escolaridade. III Seminario Iberoamericano CTS en la enseñanza de las Ciencias, p. 52-58, 2012.

FREITAS, C. M. DE; AMORIM, A. E. Vigilância ambiental em saúde de acidentes químicos ampliados no transporte rodoviário de cargas perigosas. Informe Epidemiológico do SUS, v. 10, n. 1, p. 31-42, 2001.

FREITAS, C. M. DE; PORTE, M. F. D. S. Acidentes químicos ampliados: um desafio para a saúde pública. Revista de Saúde Pública, v. 29, n. 021, p. 503-514, 1995 .

GONZALEZ, I. M. Análise de um percurso de ensino sobre o lixo urbano na perspectiva CTSA. VIII Encontro Nacional de Pesquisa em Educação de Ciências, p. $1-12,2011$.

LENARDÃO, E. J. et al. "Green chemistry" - Os 12 princípios da Química Verde e sua inserção nas atividades de ensino e pesquisa. Quimica Nova, v. 26, n. 1, p. 123129, 2003.

MORAN, J. Mudando a educação com metodologias ativas. In: SOUZA, C. A. DE; MORALES, O. E. T. (Eds.). . Convergências Midiáticas, Educação e Cidadania: aproximações jovens. [s.l.] Coleção Mídias Contemporâneas., 2015. v. IIp. 15-33. 
MORÁN, J. Mudando a educação com metodologias ativas. Coleção Mídias Contemporâneas. Convergências Midiáticas, Educação e Cidadania: aproximações jovens, v. II, p. 15-33, 2015.

NARDOCCI, A. C.; LEAL, O. L. Informações sobre Acidentes com Transporte Rodoviário de Produtos Perigosos no Estado de São Paulo: os desafios para a Vigilância em Saúde Ambiental Informations about Road Transport of Dangerous Substances in the State of São Paulo: challenges for envi. Saúde e Sociedade, v. 15, n. 2 , p. $113-121,2006$.

OSTROVSKI, C. S. A interdisciplinaridade e o uso do jornal digital: concepções dos professores de 4a séries do município de Medianeira - PR. [s.l.] UNOESTE, 2009.

PAROLI, R. M. Avaliação de Programas para Aplicação de Jornal em Sala de Aula como Recurso Pedagógico Inovador: Uma Nova Gestão do Ensino. [s.l.] PUC Campinas, 2006.

PINTO, S. L.; SGARBI, A. D. A Revista Ciência Hoje das Crianças no contexto da abordagem CTSA. Indagatio Didactica, v. 8, n. 1, 2016.

ROCHA, H. M.; LEMOS, W. DE M. Metodologias ativas: Do que estamos falando? Base conceitual e relato de pesquisa em andamento. Simpósio Pedagógico E Pesquisas Em Comunicação - IX SIMPED. Anais...Resende: 2014.

SÁNCHEZ, L. E. Avaliação de impacto ambiental. 2o ed. [s.l.] Oficina de Textos, 2015.

SANTOS, W. L. P. DOS; MORTIMER, E. F. Uma análise de pressupostos teóricos da abordagem C-T-S (Ciência - Tecnologia - Sociedade) no contexto da educação brasileira. ENSAIO - Pesquisa em Educação em Ciências, v. 02, n. 2, p. 1-23, 2002.

SILVA, C. S. DE S. DA et al. Estratégia didática para abordagem do tema sustentabilidade a partir da análise da Pegada Ecológica. Revista da SBEnBio, v. 1, n. 9, p. 7324-7331, 2016.

TOMAZELLO, M. G. C. O Movimento CTSA na Educação em Ciências. I Seminário Internacional de Ciência, Tecnologia e Ambiente, p. 7, 2009.

VALENTE, J. A.; ALMEIDA, M. E. B. DE; GERALDINI, A. F. S. Metodologias ativas: das concepções às práticas em distintos níveis de ensino. Revista Diálogo Educacional, v. 17, n. 52, p. 455-478, 2017.

Recebido em janeiro de 2019.

Aprovado em agosto de 2019. 